\title{
What do 'propositions' do for research-creation? Truth and modality in Whitehead and Wittgenstein
}

\section{David Ben Shannon \\ ESRI, Manchester Metropolitan University}

DOI: https://doi.org/10.1344/jnmr.v2i2.35891

\begin{abstract}
Research-creation is a way of researching socio-material processes as art practices. Scholars and artists pursuing research-creation often reference Whitehead's conceptualisation of the 'proposition' as a key theoretical device for speculative and creative work. However, this scholarship perhaps downplays the truth/false distinction that is essential to Whitehead's account of the proposition in favour of the proposition's potential as a speculative tool. In this paper, I explore the proposition as conceptualized by Whitehead. I think with a series of music theory concepts to theorise how Whitehead's proposition explores a modality of truth. I then discuss how the concept is taken up in research-creation. I frictionally bring together Whitehead's articulation of the proposition with that of the early Wittgenstein's. Finally, I discuss some promises and perils of this approach, with direct relevance to questions around research method and methodology in the social sciences. This article is of relevance to scholars interested in research applications of process philosophy, graduate or post-graduate students interested in an introduction to Whitehead, and researchcreation practitioners interested in the proposition.
\end{abstract}

\section{Keywords}

research-creation; proposition; Whitehead; modality; representation. 


\section{Introduction}

Research-creation, as I understand it, is a way of researching socio-material processes as art practices: it is both the doing and theorising of research (Truman \& Springgay, 2015), and is animated by a deliberately queer, crip, and anti-colonial perspective (Loveless, 2019; Shannon, 2020; Truman et al., 2019). Research-creation does not adopt any particular theoretical orientation, although many of the scholars who use the term 'research-creation' are drawn to process philosophies (e.g. Manning \& Massumi, 2014), theories of affect (e.g. Loveless, 2019; Truman \& Shannon, 2018), and feminist materialisms (e.g. Myers, 2017; Shannon \& Truman, 2020). This way of thinking about research-creation often takes up Alfred North Whitehead's conceptualisation of the proposition as a primary organising concept. ${ }^{1}$ This work emphasises Whitehead's description of the proposition as a 'lure' for speculative and creative activity, but sometimes de-emphasises the concept's roots as a speech act that can be judged to be either true or false. Whitehead expanded significantly on this "ordinary logical account of the 'proposition"' and used the term in complex ways in his later 'organic' philosophy, which is the focus of this paper (Whitehead, 1929/1978, p. 25). However, the imprint of the 'ordinary logical account' remains central in his work. In this way, if research-creation is a method of inquiry that employs the term 'proposition' in order to understand something or 'find something out', then there is much to be gained methodologically by digging deeper into Whitehead's attempt to rethink propositions and their determination of truth or falsehood. This is particularly important in the contemporary political moment, in which 'truth' is mobilised as a stand-in for cis-hetero and ableist descriptions of corporeal hierarchies and white nationalist accounts of history, and in which plurality, queerness and attempts at decolonisation are dismissed as watery truth 'relativisms'.

The idea of modality is important to how I understand truth in this paper. In linguistics, a 'modal' is an expression that qualifies the truth of a judgement. For example: it must be true that..., it cannot be true that..., or it might be true that. However, my understanding of modality is also inspired by the term's use in music theory. In music theory, modality is a description of how 'light' or 'dark' a scale sounds. Much of

\footnotetext{
${ }^{1}$ Although plenty of research-creation doesn't do this: for instance, the work of Natalie Loveless (2019). 
European harmony is animated by two primary modes: the major scale (which sounds 'light') and the minor scales (which sound 'dark'). By way of a contrast, modal harmony reconfigures the major/minor binary into seven degrees of 'majority' or 'minority', through an increasingly darkening series of semi-tonal modulations. While it still retains the major/minor distinction (which technically relates to the number of semitones between the first and third notes of the scale), modal harmony complicates the notion of the major(light)-minor(dark) dyad. This is also what modal logics do: while they retain the true/false distinction, they expand upon how that truth is conditioned. I write more about how modality is evaluated in research-creation later.

In this paper, I want to bring more specificity to the use of Whitehead's proposition in research-creation. I do so by unpacking Whitehead's conceptualisation of the proposition from Process \& Reality, and considering what this does for researchcreation, but then also exploring its implications more broadly as part of a wider deliberation about new methods and methodologies in the social-material sciences. This will entail a careful elaboration of how truth and speculation are linked in language and act; I will argue that new materialist research methods must address the problem of modal truth if they are to adequately take up and further queer, crip and anti-colonial perspectives. I begin this paper with a detailed description of the proposition as conceptualized by Whitehead. Then, I show how the proposition is used in research-creation. I include a case study on the Walking Scoring Device from my own research-creation to illustrate how this works in practice. I then reframe the speculative potential of Whitehead's understanding of the proposition by invoking Ludwig Wittgenstein's (early) articulation of the proposition in Tractatus Logico Philosophicus: I do so to argue that innovative research methods must seek a modal means to encounter the complexity of situated truth claims so that 'degrees' of truth, 'divergent' truths, and 'alternative' truths can be dissected and understood as part of a complex propositional landscape. In the next section, I begin my explication of Whitehead's proposition.

\section{Whitehead's proposition}


The 'ordinary, logical account' of the proposition is of an idea that (1) is proposed as a written statement and (2) can be judged as either true or false: for example, 'coriander is green'. However, in Process and Reality, Alfred North Whitehead (1929/1978: hereafter P\&R) suggests that the 'truth' of a proposition is linked to its capacity for speculation. For Whitehead, it is this speculative potential that is most interesting about the proposition. Whether true or false, Whitehead suggests that propositions are "tales that perhaps might be told about particular actualities" (P\&R, p. 256). A proposition, then, is "a lure for feeling" (P\&R, p. 31), where what is 'felt' is an interaction of potential and actual that brings about something new.

Bringing forth 'something new' is a key function of the proposition. As Stephanie Springgay (2016) writes: "Propositions are proposals about how things may be rather than what is" (p. 61). And this propositional 'something new' has a distinctive relationship with true/false determination. It is this latter aspect of Whitehead's proposition that I want to expand on in this paper: his contention that a restricted analytic account of the proposition as either true or false fails to reckon with the expanded modality of truth that opens up when we begin to think speculatively. In other words, for Whitehead, judging propositions in terms of a true/false binary misses the nuanced way in which truth and speculation are linked, and so "expresses only a restricted aspect of its role in the universe" (P\&R, p. 25, emphasis mine): namely, when the feeling lured by that proposition is a true/false judgement. To think beyond this restriction requires an explanation of some concepts from Whitehead's wider 'organic' philosophy, which I turn to in the next section.

Actual entities, potentialities, and relevance in Whitehead's organic philosophy.

For Whitehead, the proposition is a restriction of potential to what is actual. Whitehead describes actuality as made up of streams of thin slices of space and time. Actual things, such as tables, hats and coriander are actually a series of events, or what he sometimes calls 'actual occasions.' Each actual occasion unfolds along a stream of microscopic, micro-spatial, micro-temporal contours. In this way, according to Brian Massumi (2014), actual occasions take "the word "actual" in its etymological sense: 
"in act" (p. 59, italics in original). Whitehead uses the term concrescence to describe the contour along which each occasion unfolds. When one actual occasion has fully unfolded-or concresced-it is instantly cannibalised into 'data' for new occasions. Whitehead calls this process 'feeling' or 'prehension': fully-concresced events directly feed (or are felt into) the next events, which in turn unfold until they feed the next, and so on.

Feeling is not linear between one event and its sequel. In other words, one event does not feed directly into a second event. Rather, all previous occasions are data for all new occasions. Or, to put it another way, every concresced occasion in the whole universe has some part to play in feeding-or feeling, or prehending-into the next wave of occasions. The extent to which any individual occasion trickles into the formation of a new occasion depends on how relevant it is. And relevance (or what Whitehead calls 'definiteness') is where the proposition comes in. This is because relevance is determined by the proposition. For Whitehead, this means that the proposition restricts potential to a particular arrangement of actual occasions: or, more specifically, to the relations between those occasions (or what Whitehead calls the 'logical subject'). In so doing, the proposition 'lures feeling': it shapes how previous occasions are felt into the next occasions by determining their relevance to the current ingression. Whitehead writes:

The proposition is the potentiality of the eternal object, as a determinant of definiteness, in some determinate mode of restricted reference to the logical subjects. (P\&R, p. 257)

Or, to paraphrase:

The proposition is [the possibility that a particular potential might be applied] as a determinant of [the relevance of previous occasions to the new occasion], in some determinate mode of restricted reference to [the relations within a particular arrangement of occasions]. (P\&R, p. 257)

Now, in the ordinary, logical account of the proposition, potential is restricted to a particular configuration of occasions in such a way that how they feed into the next wave of occasions is as statements that can be judged true/false. For instance, 'it is raining' is a proposition that may be deemed to be true or false on any given occasion. 
But it also lures the speculative potential of rain on any such occasion. In this way, propositions stretch into the speculative dimensions of our research (or 'truth determination') methods. Whitehead goes on to write: "Other propositions are felt with feelings whose subjective forms are horror, disgust, or indignation" (P\&R, p. 25). In other words, human feeling shapes: (1) how the proposition is interpreted (or ingressed) by humans and (2) what human feelings it then lures.

The human feeling lured by a proposition is perhaps more obvious when that proposition is written as a prescriptive statement-e.g. 'run around in the rain!'-rather than a descriptive statement-e.g. 'it is raining'. For this reason, artists, including research-creation practitioners, often write propositions with imperative verbs (Manning, 2016a; Manning \& Massumi, 2014). Consider, for instance, the imperative "LISTEN," which Max Neuhaus famously stamped onto participants' hands before leading them on listening walks across New York City in the 1960s (Drever, 2009); In this form, the proposition solicits actions: it lures feeling through asking participants to be open to a different kind of receptivity. Similarly, music research-creation duo Oblique Curiosities' proposition 'Queer the Landscape!' during their long-distance walk along St Cuthbert's Way lured particular feelings that ended up as songs (Truman \& Shannon, 2018). In this way, the imperative verbs "LISTEN" and "Queer!" might be thought of as performing propositionally because they thread truth with speculation. Such propositions may not be subjected to a binary true/false judgement, but Whitehead might argue that they are still propositions because they restrict potential (sound or queerness) to a specific relational nexus (the city or the landscape). In this way, ordinary logical true/false accounts of the proposition are limited because they ignore how potential feelings other than true or false might be lured. However, in order to more accurately align with Whitehead's concept of the proposition, we must also discuss how these imperatives determine relevance.

To repeat myself, slightly, the proposition is a "determinant of definiteness" (P\&R, p. 257), in that it determines the relevance of the already concresced events to the new events. In this way, the proposition is a 'relevance wand'. In the context of walking through the British countryside, Oblique Curiosities' proposition to "Queer the Landscape!” conjured an interruption to the typical flow of relevance: i.e., cis-abled 
white dudes in Northern Face coats marching through the undergrowth whistling Elgar's Nimrod. Instead, 'queer the landscape' lured shrieks, polka dot dresses, and several encounters with stinging nettles, even while it was all kept within the range of acceptability by cis-abled whiteness. Similarly, in Neuhaus's listening walk, the proposition to "LISTEN" invited participants to interrupt ocular-centric modes of navigating the city. That is how the proposition is a 'determinant of definiteness': through maintaining or redirecting the flow of relevance. So far in this section, then, I have conceptualised Whitehead's proposition as restricting potential to the relations between a particular group of actual occasions, in such a way that shapes the relevance of prior occasions to future occasions. Whitehead uses the term 'feeling' (or 'prehension') to describe how prior occasions feed future occasions. In the next section, I will unpack the term 'feeling' in more detail: before I do, I want to attend to how the proposition is felt by different kinds of living and non-living entities.

It's important to note here that 'how' the proposition is ingressed-its 'subjective form'-carries a more-than-human truth value that reaches beyond the event and encompasses non-human entities. Let me explain further: Whitehead's organic philosophy is an example of what Blackman and Venn (2010) might call a 'common ontology', by which I mean that it does not theorize human social processes as distinct from 'physical' or 'natural' processes. Instead, many of his concepts are more-thanhuman, in that they apply to humans, non-human animals, non-animal life, and nonliving matter. In this way, Whitehead's philosophy is 'complete' (Williams, 2010). This is not to say that each of Whitehead's concepts applies equally to minerals, toddlers, vegetables, crustaceans and globules: again, the proposition operates through an expansive concept of relevance, and not a simplistic relativism where all truths matter equally. Rather, each entity feels and is felt within its own capacity to do so. As Whitehead writes, the proposition can "intensify, attenuate, inhibit, or transmute, without necessarily entering into clear consciousness, or encountering judgment" (P\&R, p. 263). In this way, ingression-the process of feeling and how the feeling is determined by the proposition-is as much a material process that crockery and glaciers undergo as it is an intellectual process that we might deliberately inject into a research encounter. The proposition, then, is not only a written statement or human speech act: propositional behaviour can be conceived at every level of matter. A 
written statement of a proposition is merely the proposition's objectification by a thinking human: it symbolises the interactions within the nexus of occasions to which that particular proposition restricts potential. As Sydney Hooper (1945) summarises: "the verbal statement of propositions includes words and phrases which symbolise the [feelings] necessary to indicate the logical subjects of the proposition" (pp. 64-65, emphasis in original). Note here that there are "logical subjects" within any propositional event, whether it pertains to human or non-human processes. The logical subject, for Whitehead, is the relevance of a previous event to the new event, possibly informed by a potential rather than actually being informed by one. The subjective form of the proposition is the extent to which these logical subjects are felt into the next event. Here, Whitehead is attempting to rethink the logical subject as part of his organic philosophy: to wrestle logic away from the tradition that imposes binary true/false judgements on human actants, and towards a new materialism that includes a modal logic capable of comprehending a far more complex 'truthy' landscape.

So far, I've used the word 'feeling' in quite an apolitical and ill-defined way: in the next section, I want to be more specific about how I'm conceptualising 'feeling'.

\section{What is feeling?}

Feeling, as I have already used it here, should not be conflated with emotion, although for Whitehead there are links between the two. Moreover, feeling shouldn't be equated with the sensation of touch, although that's certainly part of it too. Like the proposition, Whitehead describes 'feeling' as a more-than-human mode of experience: humans feel, but so too do non-human animals, non-animal life, and non-living matter. In this way, for Whitehead, feeling is not necessarily cognised. Instead, feeling is what Sara Ahmed (2004) might call an 'impression' of the moment of encounter: to feel a body (mind) is to press up against it and to have been felt by a body (mind) is to have had an impression left upon ones' surface. This impression may include cognition, but also includes non-cognised modes of experience. Yet, it is 'cognition' that is arguably more difficult to interpret (as those of us who draw from affect theories have probably 
thought about non-cognitive experience quite a bit): Cognition might entail microspatial, micro-temporal moments of valuation and evaluation, as Massumi emphasizes, but we must also attend to how 'value' accumulates as each event unfolds. In this way, feeling isn't (just) passive perception, but rather something that impresses upon both who is feeling and who is felt: the impressions and their e/valuation accumulates until we must engage in risky diplomacy that faces up to contested tensions, frictions and deniers all about. As Sylvia Wynter (2001) suggests, the 'feeling of being human' is sociogenetic, in that it shapes and is shaped on a material level by both biological and sociocultural structures. In this way, feeling is historied and material, and accumulates a complex web of truth valuations that are related through the proposition's sorting of relevance ('determining of definiteness'). And it is precisely for that reason that I am focusing on the ways in which the proposition carries with it a kind of modal logic, thoroughly situated in events and occasions, non-judgmental in terms of a simplistic true/false determination, and yet fully committed to distributing and engaging with a landscape of minor truths competing for relevance. In other words, 'things' feel within their own capacity to do so, and that capacity is distinctive and different from others' capacities to feel. As I aim to show in the following sections, this elaboration of Whitehead's proposition helps us to articulate what exactly is innovative about research-creation and how such methods mobilize modal logics through their use of propositions. Before that, I briefly summarise my thoughts on Whitehead so far.

\section{Summary of the proposition: How do we value truth?}

Although Whitehead doesn't outright reject the truth-value of a proposition, he's much more interested in what a proposition does. He writes: "in the real world it is more important that a proposition be interesting than that it be true. The importance of truth is, that it adds to interest" (p. 259). Importantly, Whitehead is not devaluing truth when he says this, but rather is asking us to reconsider the way we value truth. The point is crucial in properly understanding the nature of a proposition. Indeed, "interesting" is code here for 'relevance', and underscores our passionate attachments to truths, and how they 'matter' for that reason. In the next section, I discuss some examples of 
research-creation, their use of propositions, and show how this is linked to larger questions of research method in the socio-material sciences. Attention to the nature of the proposition has significant implications for how research is done. It enables researchers to conceptualise how more-than-human actants reconfigure the research occasion in which they are embedded. Finally, Whitehead's concept of the proposition shows us how speculation and truth valuation are working together (i.e., that there is not one and then the other as separate): this allows us to think methodologically in far riskier ways and thereby address the polarized, contested and settler-colonial world in which we are working. The proposition moves with intellectual and artistic rigour, opening onto new imaginaries, and at the same time unfolds through processes of valuation. In the next section, I move on to thinking about how these processes of speculation and valuation unfold through the proposition's mobilisation in researchcreation.

\section{Research-creation: Art and thinking propositionally}

Propositions are emergent: they cannot be written by or for a researching human subject. Rather, they wait in a 'restricted realm' to be objectified by a more-than-human nexus. Entering a research encounter with a written statement of the proposition taps into some aspect of this entity. Yet, having formulated and articulated a proposition in advance, you might then encounter three others along the way. You also might not encounter anything. In this way, thinking propositionally is responsive and generative, but also risky, and requires a particular ethical responsibility: to make "an ethical commitment to learning to become affected" (McCormack, 2008, p. 9). In responding and generating, the proposition cannot just shape ('lure') what is already true or about to be true, but also leverages failure, provokes the false, and speculates on 'if not this, then what?' In this way, it invokes a method of inquiry that is essentially transdisciplinary, straddling the space between disciplines without filling any of them completely (Loveless, 2019), in search of what Jack Halberstam (2011) might call "more undisciplined knowledge, more questions and fewer answers" (p. 10). In this section, I dig deeper into the nature of research-creation and the extent to which it is animated by the Whiteheadian proposition. 
The term 'research-creation' emerged as a Canadian research funding category that recognizes how artistic practice might be conducted or recognised as research (Manning \& Massumi, 2014). It was designed to recognise how artists working in universities as teachers were also engaged in research (Truman et al., 2019). It has since been taken up and theorised across the humanities and social sciences. Lots of research might be described as engaging with creative methods and quite a lot also uses the term 'research-creation'. As such, it is useful at this juncture to parse how I understand the term research-creation from other kinds of research that use creative methods, such as arts-based research or practice-as-research.

When you do research-creation, you are making art as a way of researching and theorising (Truman \& Springgay, 2015). 'Art instantiates theory,' writes Stephanie Springgay: "[some works of art] are not metaphors, nor representations of theoretical concepts; rather, some works of art event concepts" (interviewed in Truman et al., 2019 , p. 226). In other words, when you compose a song, you are doing research and theorising that research, all at the same time. Chapman \& Sawchuk (2012) illustrate four different intersections between creative practice and research: research-forcreation; research-from-creation; creative presentation of research; and research-ascreation. This model helps to explain how research-creation differs from some other approaches to arts-based research:

1. Research-for-creation is research done to inform the creation of art, but where the art itself is not research. This is something done by all artists as a way of informing their creative practice. For instance, I researched the varsoviana when composing for a production of $A$ Streetcar Named Desire.

2. Research-from-creation refers to scholarship that describes or critiques creative practice. This paper is an example of research-from-creation: it is not art, but rather a description or critical engagement. For example, Truman and Shannon (2018) describe their article about their music duo Oblique Curiosities as "Academic Liner Notes" (p. 58), in that it contextualises and describes aspects of the music without being the music.

3. Chapman and Sawchuk's third intersection is that of creative presentation of research. This refers to a process by which researchers might creatively represent their research findings. Creative presentation of research happens 
after the research has already been completed. For example, the researcher might sing their interview transcripts, decoupage them, or do an interpretive dance.

4. Finally, Chapman and Sawchuk outline creation-as-research, which is the simultaneous doing of research and creation. In creation-as-research, "creation is required in order for research to emerge" (Chapman \& Sawchuk, 2012, p. 19).

Creation-as-research illustrates my orientation to research-creation. The research and its theorisation could not exist without the act of creation because the research is done through the creative endeavour: through the epistemic unfolding of artistic practice. In this way, research-creation is what Erin Manning (2016b) describes as "a practice that thinks" (p. 27, italics in original): the practice of composing is what events “concepts-in-the-making" (Manning \& Massumi, 2014, p. 89). At the same time, research-creation as I understand it remains distinct from how I conduct my own artistic practice as a music composer because it incorporates other non-musical methods that formalise its findings for academic contexts: art may instantiate theory, but it is not then usually necessary to accompany the writing of a composition for string trio with field notes or an ethics application, or to then publish on it in an academic journal. In this way, research-creation is itself a kind of proposition, that limits creativity to the confines of what can be done with(in) the academy.

In the next section, I go on to introduce an example of a proposition: the Walking Scoring Device. In this example, the proposition is a trigger and provocation that shapes the research-encounter (Manning \& Massumi, 2014). Unlike the predetermined, prescriptive methods or schedules sometimes adopted in social inquiry, research-creation is activated by propositions, which "are not intended as a set of directions, or rules that contain and control movement, but as prompts for further experimentation and thought" (Springgay \& Truman, 2018, p. 14). Research-creation practitioners have proposed different configurations of the proposition primarily in this fashion (that is, as activators for experimentation). I think about the Walking Scoring Device in such a way. My aim here is to examine this example for how it also 
mobilizes some of the other qualities and functions of the proposition as articulated by Whitehead.

An example of a proposition in research-creation: Walking Scoring Devices.

I sometimes conduct sound walks with Walking Scoring Devices. I have done this with young children in schools, with undergraduate students, and with academics at conferences. The Walking Scoring Devices shown in Figure 1 were created for a soundwalk at Manchester Metropolitan University as part of the Summer Institute in Qualitative Research (SIQR) in July 2017. The Walking Scoring Devices consist of a short length of firm cardboard, approximately $40 \mathrm{~cm}$ long and $17 \mathrm{~cm}$ wide, a bulldog clip, a looped length of string, and a toilet roll. The toilet roll is attached to the Walking Scoring Device with the string so that the toilet roll can be unravelled across the board: this allows the user to rest on the board while scoring with their dominant hand. Depending on the opening proposition, the walker might draw graphic representations of sounds, or/and write down words or phrases they heard. The scoring episode is usually followed by a performance. Depending on the temperament of the participants, this might consist of vocal or instrumental exploration of the score, or just a nice chat. I've often used toilet roll and felt-tip pens as a graphic scoring technique with young children: this is because, unlike rectangular pieces of paper, 
toilet rolls don't have borders on their X-axis and so can be endlessly unravelled to allow a continual line or score to be drawn.

Figure 1. The picture shows a pile of five Walking Scoring Devices, already described above. A rectangular label stuck to each includes the words vibration, difference, power, propagation and non-cochlear. ${ }^{2}$

The Walking Scoring Device might be thought of as working propositionally: it creates a space for the possibility of restricting certain potentials (sounds) to a particular encounter (the walk with the device). In this way, the proposition is an enabling constraint (Manning \& Massumi, 2014). Enabling constraints propagate the researchcreation process in particular directions by closing down other avenues. Massumi (2015) describes enabling constraints as:

designed constraints that are meant to create specific conditions for creative interaction where something is set to happen, but there is no pre-conceived

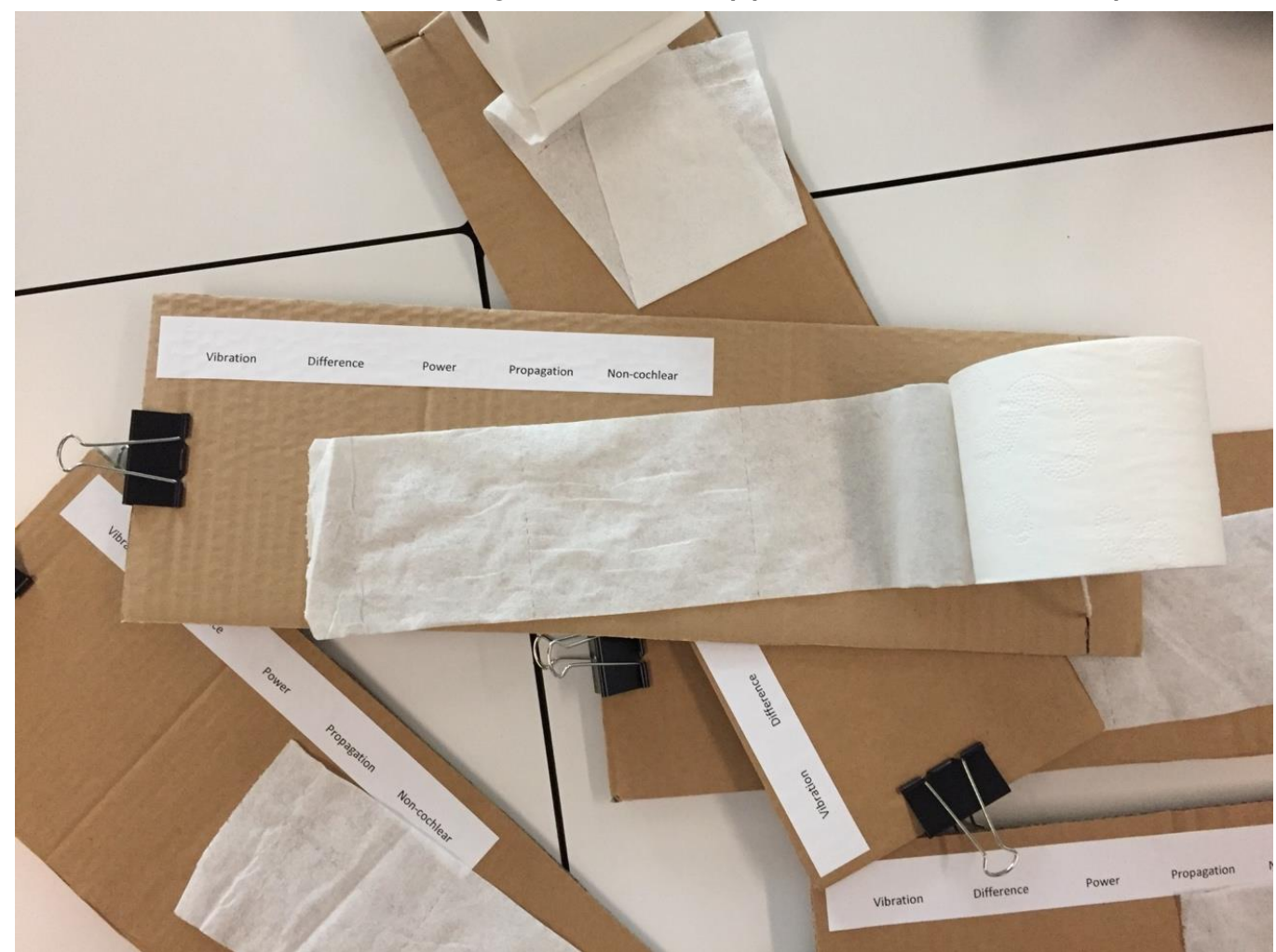

notion of exactly what the outcome will be or should be. (p. 73)

2 The walk at SIQR referenced Michael Gallagher's (2016) four conceptual filters for understanding sound affects-vibration, difference, power, propagation-plus Will Scrimshaw's (2013) notion of non-cochlear sound. 
In this way, the term 'enabling constraint' makes explicit how the proposition restricts potential to a specific nexus in order to propagate creativity. As Manning (2009) writes, "Without the rules of walking, we could invent infinitely, but the infinity would likely be chaotic... the tightness of relational movement's interval would likely be dispersed" (p. 31). The proposition might also be thought of as similar to an activation device. Springgay and Truman (2018) write that an activation device "forces something new to occur... insert[ing] itself within the walking-writing practice as a thinking-making-doing" (p. 135). An audio recording device might be an example of an activation device. Taking an audio recording device along with you on a walk pushes thought in a direction that would probably include some audio recording, while taking a Steinway or a chisel and a slab of marble would not. In other words, the potential to be creative in any given encounter depends upon the constraints or conditions placed upon that encounter. In this way, the proposition might be thought of as an activation device or enabling constraint.

The Walking Scoring Device introduces enabling-constraints. Toilet paper extends almost infinitely along one axis and so you are less likely to run out of space when composing a graphic score than with A4. Yet, at the same time, it limits what can be drawn on the other axis. Walking Scoring Devices are also activation devices. They push the walker to think about sound in a phono-graphic way (Weheliye, 2005). Moreover, the toilet paper can easily be torn, poked through with HB pencils, or turn into a soggy mush in the rain. Meanwhile, juggling toilet roll, bulldog clips, the board, and a pen is often frantic and chaotic. In this way, the devices push thought in a particular direction (e.g. "Why are we pursuing this incredibly difficult form of documentation?" or "This is ridiculous."). I often describe the Walking Scoring Devices as propositional: they constrain potential (sounds) to a particular actual nexus (toilet roll+ board+ string+ rain+ mush etc.). In so doing, I indicate both the speculative potential of the proposition, and the ways in which they unfold relevance in the later activation of the scores (vocal or instrumental exploration, or a nice chat).

One thing that I think both activation devices and enabling constraints illustrate is the need for preparation and curation in research-creation: Thinking propositionally should not be conflated with a lack of artistic rigour, or a "Let's turn up and see what happens." In research-creation, the quality of the art is the quality of the research and 
its theorisation, and so thinking propositionally and with deliberate attention to what might emerge in the encounter should not ever be understood as 'going in unprepared': in this way, it is just like any other improvisatory art practice. For example, aleatoric music incorporates elements of chance, in which throwing a dice can take you down one path or another. But the paths themselves are carefully scored and performing them relies on the skill of the instrumentalists. A further example might be modernist composer Henry Cowell's Mosaic Quartet, which consists of five movements that can be performed in any sequence, but each of the movements is carefully notated. Finally, improvisation is central to jazz music, but the improvisations are rarely a free-for-all and instead follow the harmonic modality implied in the composition's chord sequence and rely on the performers' ability to apply them in interesting ways. Similarly, then, speculation in research-creation is carefully curated: (enablingly) constrained by the proposition's ability to manage a complex terrain of values. In the next and final section of this paper, I turn to Ludwig Wittgenstein's writing on the proposition. Putting his work side-by-side with Whitehead's is generative because it (enablingly) constrains how we understand the proposition.

\section{Representation and the proposition}

I began this paper by summarising Whitehead's description of the proposition: I described this as a process by which potential is restricted to the relations within a particular group of events. I also emphasized the role of relevance in Whitehead's work, and the need to take up the question of value and pluralist truth when using this concept. I then explained how the proposition is animated in research-creation, which is mostly as a tool for speculation and which determines relevance through its commitment to queer-feminist praxis. However, it is sometimes difficult to understand how the true/false binary in Whitehead's proposition is applied in research-creation. Making truth 'irrelevant' to research findings is concerning in a world dominated by 'fake news' that mobilises "imperialist nostalgia and white supremacist fantasy" whereby "lies about the past serve the interests of power" (Nyong'o, 2019, p. 44). In other words, there is arguably a need to be more explicit as to how the proposition as mobilised in research-creation attends to this true-false 
dichotomy. For this reason, it might be helpful at this point to bring in the 'other big W' of 20th-century analytical philosophy: Ludwig Wittgenstein.

My reading of Wittgenstein here focuses on his early work in the Tractatus Logico Philosophicus (2001), which focuses on the 'picturing' relation between what something is called and what something is. This highly representational way of thinking about the proposition is quite different to how Whitehead thinks about the proposition: indeed, it's even quite different from how Wittgenstein himself thinks about the proposition in his later writing. ${ }^{3}$ From Whitehead's perspective (in Process and Reality), there can be no representation. Representation is what a human does by formulating a description of something that is separate to themself: this is impossible in Whitehead's more-than-human organic philosophy, in which each entity feels and so co-constitutes its other. Instead, Whitehead describes prehension: the material interaction of fully concresced occasions as they are felt into novel occasions. Again, this is not something that only humans do, but is felt at all levels of matter: humans, non-human animals, non-animal life, and non-living matter. In other words, a representation is supposed to be independent of the external reality that it represents, which is impossible in Whitehead's philosophy. However, I bring these two perspectives together-one representational, one non-representational-because of the way each enablingly-constrains the other: if Whitehead's proposition might be critiqued for being too capacious, the early Wittgenstein's might be critiqued for being too anally retentive. And, as Denis Flannery (2019) writes, there is a certain power in anality, "producing awe, not only by virtue of its power to contain, but also by virtue of its power... to take in the world with a view to releasing uncanny powers" (p. 109). In this way, containing or constraining Whitehead's conceptualisation of the proposition through Wittgenstein's might help us to better release its 'uncanny powers'.

In Tractatus Logico-Philosophicus, (the early) Wittgenstein (1921/2001, hereafter TLP) defines the proposition as a "picture of reality" (TPL, 4.01). ${ }^{4}$ For Wittgenstein, the proposition expresses a 'state of affairs' in such a way that it can be sensed. For instance, one can think of anything in the world: coriander, for example. Your thought

\footnotetext{
${ }^{3}$ This by way of a contrast to the complex "overlap and criss-cross" that mark his later 'language games' (Wittgenstein, 2009, p. 62).

${ }^{4}$ Numbers refer to thesis numbers.
} 
'coriander' is what Wittgenstein calls a "logical picture" (TPL, 3). Wittgenstein's proposition, then, is an expression of that picture, with "elements of the propositional sign correspond[ing] to the objects of the thought" (TPL, 3.2). For instance, the proposition 'coriander is green' names the object coriander and the potential green, which in turn relies on two elementary propositions: that (1) there is something in the world that is coriander; and that (2) things in the world can be green. Again, the representational logics underpinning Wittgenstein's proposition are not compatible with Whitehead's articulation of the proposition. For Wittgenstein, the proposition can only be either true or false. He writes, "A proposition must restrict reality to two alternatives: yes or no. In order to do that, it must describe reality completely" (TPL, 4.023). So, the proposition 'coriander is green' is true because coriander is green. The proposition would have been false if coriander isn't green, whether because: (1) coriander doesn't exist, (2) things in the world cannot be green, or (3) coriander exists and things can be green, but coriander isn't one of the green things. A proposition, then, as described by the early Wittgenstein, linguistically depicts an arrangement of objects in much the same way that a photograph might visually depict them: Either the photograph accurately depicts an arrangement as it truly is, or it doesn't. There is no in-between.

This conceptualisation of the proposition (found in Wittgenstein's early work and not so much in the later Philosophical Investigations) is not commensurate with Whitehead's. Indeed, it's only the following thesis that gives us just a tiny way to link these two extremely different logics:

A gramophone record, the musical idea, the written notes, and the sound waves, all stand to one another in the same internal relation of depicting that holds between language and the world. They are all constructed according to a common logical plan. (TPL, 4.014)

Here, Wittgenstein invests in a correlation theory of truth, where the truth of the proposition is determined by whether or not it accurately describes (i.e. correlates with) the actual world. Correlation theories of truth are highly representational and very different from the speculative, more-than-representational thought of Whitehead. However, I think there is something to be gained by tapping the Tractatus for some 
negotiation of 'truth'. Consider how musical notation indicates the arrangement of fingers, motion, keys, hammers, felt and strings that allow me to play Debussy's 'Clare de Lune' from Suite Bergamasque: like the written music score, the proposition expresses an arrangement of objects (a 'state of affairs') in such a way that it can be sensed. It's this relationship between written score and sound waves that I want to dwell on for the remainder of this paper: I do so by thinking about the specificity of what my piano does when I play 'Clare de Lune.'

My piano is a Yamaha U3. It's an upright: finished in finger-print magnet glossy black, except for a deep gouge above the pedalboard from one of its previous owners. Grumps (my grandad) gave me the down-payment for the piano on my $18^{\text {th }}$ birthday, and I paid off the rest of it by washing dishes in a nursing home in 48 monthly instalments. The felt on its hammers has hardened over its lifetime and it now has an unusually bright sound: I keep meaning to get it needled. For the time being, assuming I get all the notes right (which in itself is fairly unlikely), 'Clare de Lune' played on my U3 with its gouge and its bright hammers will sound distinctly different to any other similar-aged U3. That's before its complicated by the dishwashing, my popular and jazz rather than classical training, Grumps crying the first time he heard me practising it for my final performance at music school (where, without the score, I flubbed it, gruesomely), and the teeny rhythmic divergences that Romantic impressionist music invites.

Debussy would definitely have disapproved of my wrong notes when playing 'Clare de Lune'. They are definitively wrong: false, as in not described by the score. On the other hand, and while I think Debussy would still probably have hated it, the mawkish rubato I'm prone to (over)indulging in is not 'false': a mawkish but accurate performance is still strictly a true performance. I don't know how he would have felt about my brightsounding hammers but, again, they are irrelevant to the accuracy of the performance. This is because the written score is already a compromise and a deviation: a way of expressing something that can't be completely notated. It's impossible to notate, for instance, precisely how much to tenuto each note from bar 15. Similarly, the ambiguous direction in bar 27 to give un poco mosso begs the question: 'a little more what?!' Debussy probably wasn't angling for more wrong notes, but also isn't being particularly specific: More volume? More speed? More 'temperament'? More gouges?! 
Similarly, Debussy's 'Minstrels' from Preludes I includes the direction that a particular motif should be played en dehors-literally, 'in the outside'. In this way, the score allows for variation: it has to, because of the impossibility of writing notation with enough detail to completely express the work. In this way, the space for the variation that must be included as part of a 'true' performance is partially notated into the work.

Lest it is tempting to think this is a feature of impressionist Romantic-era music, even the most stringent examples of earlier classical music include these variations. Before the invention of the earliest pianos around 1700, playing expressively on keyboard instruments was very difficult: dynamics were impossible on a harpsichord. Even if the harpsichord includes two or three manuals, each with a different dynamic range, that's still only three dynamics. For this reason, compositions for keyboard instruments included ornaments. Ornaments, such as trills, turns, acciaccatura and appoggiatura (grace notes), and mordents allowed the performer to improvise and add expression and character to their performance. For instance, Bach's Goldberg Variations include turns, which indicate that the performer should play not just the written note but the adjacent two notes as well, in a rhythm of the performer's own choosing. Likewise, the gorgeous fuzzy acoustic distortion on Jacques Loussier's 1959 performance of Bach's Prelude in C Major (on Play Bach Vol. 1) also cannot be scored.

My point across all these examples is that any correspondence theory of truth that separates the proposition from the world, and then worries whether it might accurately describe that world, always entails some leakiness. The 'common logical plan' that Wittgenstein suggests unites a score, sound waves and a gramophone recording is 'relevance': the speculative/propositional glue that Whitehead affirms in how the proposition shapes feeling. I know it is clumsy to bring these two together, but I am interested in how this uncomfortable, generatively 'frictional' (Puar, 2012) conjunction might assist us in thinking about research-creation. Consider the correlation between any individual recording and the sound waves it produces: while the recording might go unchanged, there is a leakiness to how that recording might be further transformed by a different record player, the same record player with a different listener, or the same listener on different days. And all of this is to neglect how the recording itself is 
subject to all manner of mechanical and computational distortion over time (Weheliye, 2005). In this way, while a recording might register an accurate, true performance of a work, there's no telling what might happen to it next! In other words, neatly parsing true from false is important for determining how a performance is accurate or compelling, but it's precisely that mix of accuracy and compelling that brings us back to the concept of relevance. I think the idea of a variation within 'accuracy' is hugely significant for thinking about research-creation as it allows us to move away from the idea of propositions as working only within binary logics, even whilst affirming the significance of issues of relevance, and so demands we bring to bear a more nuanced modal logic that stretches truth across a spectrum of degree.

Modal logics have evolved over the last century to help us think about the temporal and situated nature of truth determination. As I've already explained, modality in linguistics refers to the way our propositions are always qualified, modulating our epistemic commitment to the truth of the claim, which is then deemed necessarily true, possibly true, or perhaps beyond truth. When added to the proposition, modals don't just propose what is already actually true but allow us to explore situated truths. Crucially, modality is not a matter of 'how true' something is but instead addresses the variation that truth contains within itself: mordents, flat-felted hammers, un poco mosso, and fuzzy acoustic distortion.

\section{Closing thoughts: en dehors and implications for method}

The use of the arts as an approach to conducting and/or disseminating research is proliferating in qualitative educational research. This is particularly true of research that draws from theories of affect, including the feminist new materialisms. The turn to arts-based methods, then, appears to be because of a perception that these methods might be able to better attend to some of the issues l've touched on (parenthetically) in this paper: the crisis of representation, the agency of the morethan-human, and our contested contemporary political ecology. Yet, I think we need to be careful of how we apply such methods. Springgay and Truman (2018) contend that the incommensurability of materialist ontologies and traditional methods doesn't necessarily call for 'new' (or even an end to) methods; Rather, it is the procedural and 
extractional orientation towards methods that should be undone. Similarly, Elizabeth St. Pierre (2019) contends that methodological uptake of the ontological turn must inform research practice and not just the presentation or theorization of the research findings. She writes: "a study cannot be made post qualitative after the fact" (p. 10). This is not to say that representational use of the arts is necessarily 'bad' or uninteresting, but just that it doesn't overcome the logics of representation, and so arguably isn't 'post'-qualitative, and definitely isn't an example of research-creation.

Elizabeth de Freitas (2017) pushes the critique further, suggesting five characteristics of research method: her ideas resonate strongly with my discussion of Whitehead's proposition and its potential use in research-creation. De Freitas argues that research methods often embody an obsession with novelty, positioning the researcher as the 'creator of concepts', marking ones' contribution with an easily identifiable keyword (that probably includes some brackets and a hyphen). This is, of course, because of the push to publish (publish or die!) and be cited (be cited or die!) in the university. So, in addition to excluding various kinds of truths (restricted perspectives), research methods must be interrogated for how they desire to mark new ground as an act of building new knowledge empires. De Freitas also shows how methods establish regimes of work and labour, echoing the insights of St. Pierre (2019) and Sarah E. Truman (2021) and their critiques of the procedural platitudes of qualitative and 'post'qualitative research respectively. Raising these issues brings us back to the hard questions of truth in a pluralist political ecology. But (most importantly for the purposes of this paper) de Freitas elaborates how research methods can be:

emergent, innovative, and historically transformational... new research methods can emerge out of floods of data and information, and new research methods can... subvert the slow deliberative time of the 'human' subject, by plugging into a more-than-human worldly becoming. (de Freitas, 2017, p. 29)

Research-creation is a practice for understanding something. Employing the proposition as a primary organising concept is what enables research-creation to be emergent, situated, feminist and responsive. However, these mobilisations do not explicitly attend to how these deliberations convene around truth. This raises a problematic proposition of its own: If it doesn't matter if the proposition is true or false, 
then the 'understanding' generated through research-creation might be argued to have no link to a truth determination: this is potentially problematic. However, if methods for truth determination are imagined and developed to be more expansive-through rethinking the proposition within a modal logic-then we are getting somewhere. What I'm reaching for, then, is how the proposition-as described by Whitehead as I frictionally rub him up against Wittgenstein-might be employed in research-creation as part of new methodologies emerging in the new transdisciplinary post-humanities.

As l've already touched on, ever so briefly, it's important in the contemporary, contested settler-colonial political ecology to keep a hold of the 'false'. As Tavia Nyong'o (2019) writes: "We undoubtedly live in an era of malignant imperialist nostalgia and white supremacist fantasy. We daily observe how lies about the past serve the interests of power" (p. 44). Populist conservative organisations and politicians have gained a good deal of traction through false propositions that shore up these nostalgic fantasies. For instance, Conservative British minister Priti Patel's statement that she 'would not take the knee to the Black Lives Matter movement,' which relies on the false elementary propositions that 'taking the knee to the Black Lives Matter movement' is something that people do and that Priti Patel might find herself invited to take such a knee. Or the very public debate that removing statues of slave traders from public spaces is an attempt to 'erase history', which again relies on the false elementary propositions that maintaining such statues is an accurate account of history and removing them is capable of erasing that history. Or, finally, the trans-antagonist claim that 'sex is real', which falsely implies that somebody else (presumably trans activists, allies and scholars) is arguing that sex is 'unreal'. These are demonstrably false propositions that get taken up uncritically and in damaging ways. So, as Nyong'o (2019) asks, "what is a queer fabulist to do?” (p. 44).

Just like everything else to do with research-creation, the proposition is not a free-forall, but an exercise in exacting specificity: a rigorous curation of fabulative, speculative intensities and flows that most definitely keeps hold of 'false': of wrong notes, bad politics and crap art. At the same time, just like the turns and mordents Bach wrote into the Goldberg Variations, the truth-value of a proposition has a modality to it: a capacity for free play between necessity, possibility and impossibility that comes like Debussy's en dehors and un poco mosso: from the outside, asking us for a little more. 
In this way, a modal understanding of truth leaves room for distortion, for brightsounding flat-felted hammers, and everything else that is true but in excess of the score. The modal landscape of the proposition invites 'fabulation of the false' but doesn't cast out valuation completely: there is truth determination in our relation to the proposition, which operates according to a relevance engine that is modal rather than binary.

\section{Acknowledgements}

I would like to thank Professor Elizabeth de Freitas for her generous support while writing this article (and pushing me to read Whitehead in the first place!), the anonymous reviewers for their feedback, and Grumps for my Yamaha U3.

\section{Bibliography}

Ahmed, Sara (2004). The cultural politics of emotion. Edinburgh University Press.

Blackman, Lisa, \& Venn, Couze (2010). Affect. Body \& Society, 16(1), 7-28. https://doi.org/10.1177/1357034X09354769

Chapman, Owen, \& Sawchuk, Kim (2012). Research-Creation: Intervention, Analysis and "Family Resemblances." Canadian Journal of Communication, 37(1), 5-26. https://doi.org/10.22230/cjc.2012v37n1a2489

de Freitas, Elizabeth (2017). The temporal fabric of research methods: Posthuman social science and the digital data deluge. Research in Education, 98(1), 27-43. https://doi.org/10.1177/0034523717723386

Drever, John Levack (2009). Soundwalking: Creative listening beyond the concert hall. In J. Saunders (Ed.), The Ashgate Research Companion to Experimental Music (pp. 163-192). Ashgate Publishing Limited.

Flannery, Dennis (2019). In. In L. Berlant (Ed.), Reading Sedwick (pp. 92-112). Duke University Press.

Gallagher, Michael (2016). Sound as affect: Difference, power and spatiality. Emotion, 
Space and Society, 20, 42-48. https://doi.org/10.1016/j.emospa.2016.02.004

Halberstam, Jack (2011). The queer art of failure. Duke University Press.

Hooper, Sydney E. (1945). Whitehead's philosophy: "Propositions and consciousness." Philosophy, 20(75), 59-75.

Loveless, Natalie (2019). How to make art at the end of the world: A manifesto for research-creation. Duke University Press.

Manning, Erin (2009). Relationscapes: Movement, art, philosophy. MIT Press.

Manning, Erin (2016a). Ten propositions for research-creation. In N. Colin \& S. Sachsenmaier (Eds.), Collaboration in Performance Practice: Premises, Workings and Failures (pp. 133-141). Palgrave Macmillan UK. https://doi.org/10.1057/9781137462466_7

Manning, Erin (2016b). The minor gesture. Duke University Press.

Manning, Erin, \& Massumi, Brian (2014). Thought in the act: Passages in the ecology of experience. University of Minnesota Press.

Massumi, Brian (2014). Envisioning the virtual. In M. Grimshaw (Ed.), The Oxford handbook of virtuality (pp. 55-70). Oxford University Press.

Massumi, Brian (2015). Politics of affect. Polity Press.

McCormack, Derek P. (2008). Thinking-Spaces for Research-Creation. Inflexions, 1(1). http://www.inflexions.org/n1_Thinking-Spaces-for-Research-Creation-by-DerekP-McCormack.pdf

Myers, Natasha (2017). Ungrid-able ecologies: Decolonizing the ecological sensorium in a 10,000 year-old naturalcultural happening. Catalyst: Feminism, Theory, 3(2), 1-24. https://doi.org/http://dx.doi.org/10.28968/cftt.v3i2.216

Nyong'o, Tavia (2019). Afro-Fabulations: The queer drama of Black life. New York University Press.

Puar, Jasbir K. (2012). "I would rather be a cyborg than a goddess": Becomingintersectional in assemblage theory. PhiloSOPHIA, 2(1), 49-66. https://doi.org/10.1353/phi.2012.0006 
Scrimshaw, Will (2013). Non-cochlear sound: On affect and exteriority. In M. Thompson \& I. Biddle (Eds.), Sound music affect: Theorizing sonic experience (pp. 2743). Bloomsbury.

Shannon, David B. (2020). Neuroqueer(ing) Noise: Beyond 'mere inclusion' in a neurodiverse early childhood classroom. Canadian Journal of Disability Studies, 9(5), 489-514. https://cjds.uwaterloo.ca/index.php/cjds/article/view/706/968

Shannon, David B. \& Truman, Sarah E. (2020). Problematizing Sound Methods Through Music Research-Creation: Oblique Curiosities. International Journal of Qualitative Methods, 19. https://doi.org/10.1177/1609406920903224

Springgay, Stephanie (2016). Meditating with bees: Weather bodies and a pedagogy of movement. In N. Snaza, D. Sonu, S. Truman, \& Z. Zaliwska (Eds.), Pedagogical matters: New materialisms and curriculum studies (pp. 59-73). Peter Lang.

Springgay, Stephanie, \& Truman, Sarah E. (2018). Walking methodologies in a morethan-human world: WalkingLab. Routledge.

St. Pierre, Elizabeth A. (2019). Post Qualitative Inquiry in an Ontology of Immanence. Qualitative Inquiry, 25(1), 3-16. https://doi.org/10.1177/1077800418772634

Truman, Sarah E. (2021). Feminist speculations and the practice of research-creation: Writing pedagogies and intertextual affects. Routledge.

Truman, Sarah E., Loveless, Natalie, Manning, Erin, Myers, Natasha, \& Springgay, Stephanie. (2019). The intimacies of doing research-creation: Sarah E. Truman interviews Natalie Loveless, Erin Manning, Natasha Myers, and Stephanie Springgay. In N. Loveless (Ed.), Knowings and Knots (pp. 221-250). University of Alberta Press.

Truman, Sarah E., \& Shannon, David B. (2018). Queer sonic cultures: An affective walking-composing project. Capacious: Journal for Emerging Affect Inquiry, 1(3), 5877. https://doi.org/10.22387/CAP2018.19

Truman, Sarah E., \& Springgay, Stephanie (2015). The primacy of movement in research-creation: New materialist approaches to art research and pedagogy. In M. Laverty \& T. Lewis (Eds.), Art's teachings, teaching's art: Philosophical, critical, and educational musings (pp. 151-162). Springer. 
Weheliye, Alexander G. (2005). Phonographies: Grooves in sonic Afro-modernity. Duke University Press.

Whitehead, Alfred North (1978). Process and Reality: An essay in cosmology (corrected edition). The Free Press. (1929).

Williams, James (2010). Immanence and transcendence as inseparable processes: On the relevance of arguments from Whitehead to Deleuze interpretation. Deleuze Studies, 4(1), 94-106. https://doi.org/10.3366/e1750224110000851

Wittgenstein, Ludwig (2001). Tractatus Logico-Philosophicus. Routledge. (1921). Wittgenstein, Ludwig (2009). Philosophical investigations. (P. Hacker, G. Anscombe, \& J. Schulte trans.). Wiley-Blackwell. (1953).

Wynter, Sylvia (2001). Towards the sociogenic principle: Fanon, identity, the puzzle of conscious experience, and what it is like to be "Black." In M. F. Durán-Cogan \& A. Gómez-Moriana (Eds.), National Identities and sociopolitical changes in Latin America (pp. 30-66). Routledge.

\section{Author Information}

\section{David Ben Shannon (David.Shannon@mmu.ac.uk)}

David Ben Shannon is a PhD student in the Education and Social Research Institute, Manchester Metropolitan University. His current research explores neurodiversity in the early childhood classroom, and draws from theories of affect, queer theory, and critical disability studies. He is a composer and musician, and is one half of electronica/glitch-folk research-creation music duo Oblique Curiosities. His pronouns are he/him. 